\title{
Association between furosemide administration and outcomes in critically ill patients with acute kidney injury
}

Guang-ju Zhao ${ }^{1 \dagger}$, Chang Xu ${ }^{1 \dagger}$, Jian-chao Ying ${ }^{1}$, Wen-biao Lü ${ }^{1}$, Guang-liang Hong ${ }^{1}$, Meng-fang Li , Bing Wu', Yong-ming $\mathrm{YaO}^{2^{*}}$ and Zhong-qiu Lu ${ }^{1^{*}}$

\begin{abstract}
Background: Although current guidelines for AKI suggested against the use of furosemide in AKI management, the effect of furosemide on outcomes in real-world clinical settings remains uncertain. The aim of the present study was to investigate the association between furosemide administration and outcomes in critically ill patients with AKI using real-world data.

Methods: Critically ill patients with AKI were identified from the Medical Information Mart for Intensive Care (MIMIC)-III database. Propensity score (PS) matched analysis was used to match patients receiving furosemide to those without diuretics treatment. Linear regression, logistic regression model, and Cox proportional hazards model were used to assess the associations between furosemide and length of stay, recovery of renal function, and inhospital and 90-day mortality, respectively.

Results: A total of 14,154 AKI patients were included in the data analysis. After PS matching, 4427 pairs of patients were matched between the patients who received furosemide and those without diuretics treatment. Furosemide was associated with reduced in-hospital mortality [hazard ratio (HR) $0.67 ; 95 \% \mathrm{Cl} 0.61-0.74 ; P<0.001$ ] and 90-day mortality [HR 0.69; 95\% Cl 0.64-0.75; $P<0.001]$, and it was also associated with the recovery of renal function [HR $1.44 ; 95 \% \mathrm{Cl} 1.31-1.57 ; P<0.001]$ in over-all AKI patients. Nevertheless, results illustrated that furosemide was not associated with reduced in-hospital mortality in patients with AKI stage 0-1 defined by UO criteria, AKI stage 2-3 according to SCr criteria, and in those with acute-on-chronic (A-on-C) renal injury.

Conclusions: Furosemide administration was associated with improved short-term survival and recovery of renal function in critically ill patients with AKI. Furosemide was especially effective in patients with AKI UO stage 2-3 degree. However, it was not effective in those with AKI SCr stage 2-3 and chronic kidney disease. The results need to be verified in randomized controlled trials.
\end{abstract}

Keywords: Furosemide, Diuretic, Acute kidney injury, Critical care, Mortality

\footnotetext{
*Correspondence: c_ff@sina.com; Izq_640815@163.com

${ }^{\dagger}$ Guang-ju Zhao and Chang Xu contributed equally to this work.

${ }^{2}$ Trauma Research Center, Fourth Medical of the Chinese PLA General Hospital, Beijing 100048, People's Republic of China

${ }^{1}$ Emergency Intensive Care Unit, Emergency Department, The First Affiliated Hospital of Wenzhou Medical University, Wenzhou 325000, People's Republic of China
}

C C The Author(s). 2020 Open Access This article is licensed under a Creative Commons Attribution 4.0 International License, which permits use, sharing, adaptation, distribution and reproduction in any medium or format, as long as you give appropriate credit to the original author(s) and the source, provide a link to the Creative Commons licence, and indicate if changes were made. The images or other third party material in this article are included in the article's Creative Commons licence, unless indicated otherwise in a credit line to the material. If material is not included in the article's Creative Commons licence and your intended use is not permitted by statutory regulation or exceeds the permitted use, you will need to obtain permission directly from the copyright holder. To view a copy of this licence, visit http://creativecommons.org/licenses/by/4.0/ The Creative Commons Public Domain Dedication waiver (http://creativecommons.org/publicdomain/zero/1.0/) applies to the data made available in this article, unless otherwise stated in a credit line to the data. 


\section{Background}

Acute kidney injury (AKI) is common in critically ill patients and carries a high morbidity and mortality rate. In clinical practice, diuretics, in particular loop diuretics, are often used to prevent AKI by increasing the urine output (UO) [1, 2]. Furosemide is the most common loop diuretic used in critically ill patients, and numerous clinical trials have been designed to evaluate the effectiveness of it in AKI. Some studies found that furosemide exhibited neutral or deleterious effects in AKI treatment [2-4]. In contrast, several studies have suggested that furosemide might reduce the need for renal replacement therapy (RRT) and attenuate the severity of AKI $[5,6]$. So, the effect of furosemide on outcomes of critically ill patients with AKI is still controversial and needs to be further investigated in large-scale studies. We hypothesized that furosemide administration was associated with decreased mortality in critically ill patients with AKI.

Current guideline recommends defining AKI based on serum creatinine ( $\mathrm{SCr}$ ) increase and oliguria, and staging AKI by the worse of the two parameters [7]. To explore the effect of diuretics on outcomes of AKI, studies often included patients using both $\mathrm{UO}$ and $\mathrm{SCr}$ criteria [2, 8]. However, Kellum and colleagues in a study of 23,866 AKI patients found that the mortality of patients with AKI defined by UO criteria was much lower than those staged according to both UO and SCr criteria [9]. Studies also found that the patient's UO criterion for AKI did not usually match well with the patient's respective SCr criterion $[10,11]$. As oliguria is the main reason for furosemide use in clinical practice, oliguric AKI should be considered as a single population in evaluating the effect of diuretics on outcomes in AKI patients. In addition, it has been noticed that the association between poor outcomes and furosemide was more frequently reported in cohorts with higher $\mathrm{SCr}(>3.0 \mathrm{mg} / \mathrm{dl})$ while insignificant in patients with mild AKI $(<2.0 \mathrm{mg} / \mathrm{dl})$ [12]. The result suggested that the curative effect of furosemide on AKI patients may be influenced by the increased degree of SCr. The second aim of this study was to examine the association of furosemide use and mortality outcome among patients with different AKI stages by $\mathrm{UO}$ or $\mathrm{SCr}$ criteria or both.

\section{Materials and methods Sources of data}

The data of the present study were collected from a large critical care database named Multiparameter Intelligent Monitoring in Intensive Care Database III (MIMIC III). MIMIC III is a publicly and freely available database which is well described in previous papers [13, 14]. In brief, MIMIC III database contains ICU patient data from the Beth Israel Deaconess Medical Center (single) between 2001 and 2012. This database was approved by the
Institutional Review Boards (IRB) of the Massachusetts Institute of Technology (MIT). After successfully completing the National Institutes of Health (NIH) Web-based training course and the Protecting Human Research Participants examination (no. 7574829), we were given the permission to extract data from MIMIC III.

\section{Population selection criteria}

Patients meeting criteria for AKI following the Kidney Disease: Improving Global Outcomes (KDIGO) criteria on admission were considered eligible for study inclusion. KDIGO criteria are as follows [7]: increase in $\mathrm{SCr}$ to $\geq 1.5$ times baseline must have occurred within the prior 7 days; or a $\geq 0.3 \mathrm{mg} / \mathrm{dl}$ increase in $\mathrm{SCr}$ occurred within $48 \mathrm{~h}$; or urine volume $<0.5 \mathrm{ml} / \mathrm{kg} / \mathrm{h}$ for $6 \mathrm{~h}$ or more. Minimum of the $\mathrm{SCr}$ values available within the 7 days before admission was used as the baseline $\mathrm{SCr}[15,16]$. When the preadmission $\mathrm{SCr}$ was not available, the first $\mathrm{SCr}$ measured at admission was used as the baseline SCr [17]. AKI stages were defined by both $\mathrm{SCr}$ and the volume of UO during the first $48 \mathrm{~h}$ after ICU admission. AKI stages defined by $\mathrm{SCr}\left(\mathrm{AKI}^{\mathrm{Cre}}\right)$ or $\mathrm{UO}\left(\mathrm{AKI}^{\mathrm{UO}}\right)$ alone were recorded respectively. If patients were admitted multiple times, only the first stay was analyzed. Patients with age $<18$ years old, and those who were discharged or died within $48 \mathrm{~h}$ after ICU admission were excluded. Patients were also excluded from the study if they received diuretic drugs $48 \mathrm{~h}$ after ICU admission or if more than $5 \%$ of the potential risk variables for death were missing.

\section{Data collection and definitions}

The data on the first day of ICU admission were extracted from MIMIC III using Structured Query Language (SQL) with Navicat Premium (version 12.0.28) including age, gender, ethnicity, admission type, comorbidities, simplified Acute Physiology Score II (SAPSII), sequential organ failure assessment (SOFA) score, mean arterial pressure (MAP), SCr level, use of vasopressors and inotropes, daily fluid input, fluid balance, fluid types, cardiac surgery, RRT, and mechanical ventilation. Sepsis was defined as life-threatening organ dysfunction caused by a dysregulated host response to infection (sepsis 3.0). In the present study, patients with documented or suspected infection plus an acute increase of $\geq 2$ SOFA points were recorded as sepsis. The estimated glomerular filtration rate (eGFR) was calculated using the modification of diet in renal disease (MDRD) formula [18].

The information on diuretic drugs used including drug names, dose, route, start time, and end time were also collected. A Python script was written by us for calculating the dose of furosemide and for collecting the administration route of it. Total furosemide dose was defined as the intravenous administration plus $0.5 \times$ oral dose. In evaluating the dose-dependent effect of furosemide on 
the outcomes of AKI patients, the data of furosemide dose were presented as milligram per kilogram per day.

In the present study, all variables had less than $25 \%$ missing values. Single imputation was used to impute missing values in variables including MAP, serum creatinine and eGFR on admission, and weight and the volume of UO on ICU discharge (see additional file 1: Table S1).

\section{Endpoints}

In-hospital mortality was the primary endpoint. 90-day mortality, recovery of renal function, length of stay (LOS) in hospital, and ICU were considered as secondary outcomes. Recovery of kidney function was defined as being discharged from ICU with SCr below 1.5 times the baseline value and normal UO $(>0.5 \mathrm{ml} / \mathrm{kg} / \mathrm{h}$ for $24 \mathrm{~h}$ on discharge).

\section{Statistical analysis}

Continuous variables in the present study were all expressed by median [interquartile range (IQR)] and the differences between groups were identified with the Mann-Whitney test because of their non-normal distribution. Categorical variables were expressed as the number and percentage, and comparisons between groups were made using the chi-square test or Fisher's exact test as appropriate.

To estimate the association between furosemide administration and outcomes among critically ill patients with AKI, propensity-score matching was performed in our study by a greedy nearest neighbor matching using a caliper of 0.2 standard deviations of the logit of the estimated propensity score. Patients were matched in a 1:1 ratio, such that each patient who was treated with furosemide within $48 \mathrm{~h}$ after ICU admission was matched to 1 patient without diuretic treatment. Standardized mean difference (SMD) was calculated to evaluate the efficiency of PSM in reducing the differences between the two groups.

Cox regression model was used for estimating the relationships between administration of furosemide and mortality outcomes adjusting for confounding variables selected based on $p$ value $<0.05$ in univariate analysis and potential confounders judged by clinical expertise of our team and was used for estimating the relationships between quintiles of furosemide dose and mortality. Impact of furosemide use on the recovery of renal function was estimated using logistic regression model adjusting for age, gender, and SAPSII score. Linear regression was used to evaluate the association between furosemide use and length of stay, and the hazard ratios (HR) were calculated using the formula $\mathrm{HR}=e^{\beta \mathrm{i}}$.

Stratification analysis was conducted to explore whether the association between furosemide administration and in-hospital mortality differed across various subgroups classified by different AKI severity based on $\mathrm{SCr}$ or UO criteria or both, chronic kidney disease, acute respiratory distress syndrome (ARDS), heart failure, and sepsis. The relationship between the daily dose of furosemide and inhospital mortality was also evaluated, and the analysis was performed in the population after PSM matching.

Statistical analysis was performed using IBM SPSS Statistics version 22.0 (IBM, Armonk, NY, USA) and R 3.5.3 software for windows and Python 3.7.3. A $P$ value $<0.05$ was considered statistically significant.

\section{Results \\ Basic characteristics}

During the study period, 25,775 critically ill patients were admitted with AKI. After excluding the patients according to the exclusion criteria, 14,154 eligible patients were enrolled. Seven thousand eight hundred eighty-five patients were exposed to furosemide within the first $48 \mathrm{~h}$ after ICU admission, and 6269 patients did not receive diuretics (Fig. 1).

As shown in Table 1, there were significant differences in AKI stages, ethnicity, and admission types between the furosemide group and the non-diuretic group. The mean age was significantly higher, and the levels of MAP were significantly lower among furosemide-treated patients on admission. The levels of SCr were significantly higher and eGFR was lower in the non-diuretic group when compared with the furosemide group. Vasopressors and inotropes use were more common in the furosemide group. Patients with heart failure, acute lung edema, and those who underwent cardiac surgery were more likely to be given furosemide. The volume of daily fluid input and the incidence of colloid use were higher among furosemide-treated patients. The proportion of patients with positive fluid balance in the furosemide group was greater than that in non-diuretic group.

\section{Relationship between furosemide and outcomes}

Cox proportional hazard model was used to examine the difference in mortality outcomes between the two groups. In pre-matched cohort, furosemide use was associated with reduced in-hospital mortality (HR 0.63; 95\% CI $0.58-0.69 ; P<0.001$ ) and 90 -day mortality (HR 0.66 ; 95\% CI $0.61-0.70 ; P<0.001)$ after adjusting for possible confounding factors associated with mortality (Table 2 and Additional file 1: Table S2). Using the logistic regression model, the impact of furosemide use on the recovery of renal function was estimated, and we found that furosemide use was also associated with an increased chance of renal function recovery (HR 1.29; 95\% CI 1.21-1.38; $P<0.001)$. Nevertheless, furosemide use was associated with longer length of stay (LOS) in ICU and hospital (Table 2). 


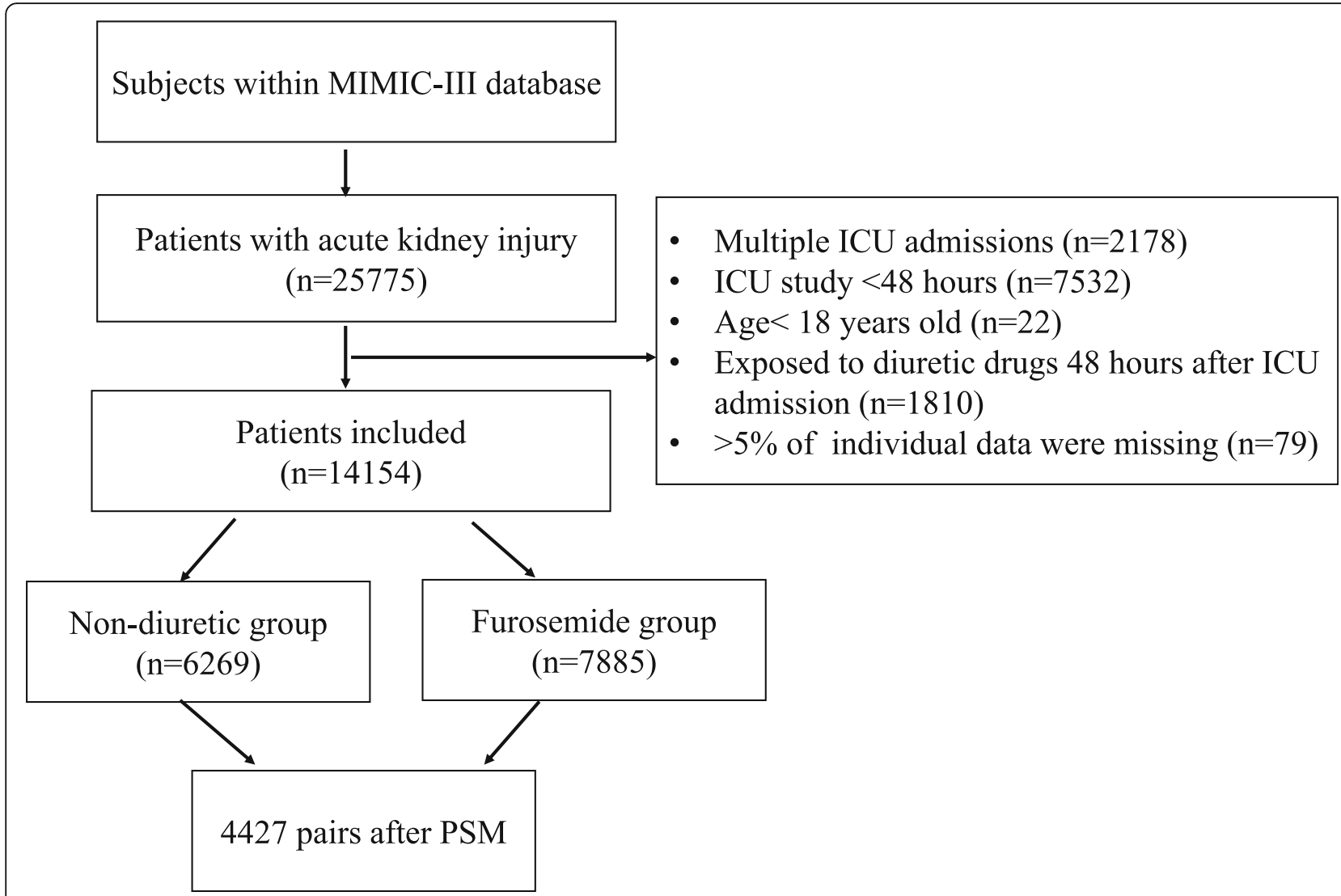

Fig. 1 Flowchart of Included Patients. MIMIC III: Multiparameter Intelligent Monitoring in Intensive Care Database III; ICU: intensive care unit; PSM: propensity-score matching

In PSM, 4427 patients who received furosemide were matched with 4427 patients who did not receive diuretics. In Table S3 (see Additional file 1), the matched patient characteristics were compared, and the standardized mean differences (SMD) for all the individual covariates were provided. After matching, the baseline profiles were well balanced between the two groups with SMDs that were less than 10\% for all variables (Table S3 and Additional file 1: Figure S1). Similar to the results in the pre-matched model, furosemide was associated with reduced in-hospital mortality (HR 0.67; 95\% CI 0.61-0.74; $P<0.001$ ), and it was also associated with improved 90day survival (HR 0.69; 95\% CI 0.64-0.75; $P<0.001$ ) after PSM (Table 2). The results showed that the recovery of renal function was promoted by furosemide in AKI patients (HR 1.44; 95\% CI 1.31-1.57; $P<0.001$ ) (Table 2). Additionally, furosemide was also associated with increased LOS in hospital (HR 1.71; 95\% CI 1.04-2.85; $P=0.032$ ) (Table 2).

When taking the dose of furosemide into consideration, we found that receiving $\leq 1.10 \mathrm{mg} / \mathrm{kg} /$ day was associated with a reduced risk of in-hospital mortality when compared with the non-diuretic group (Table S4). High-dose furosemide $(>1.10 \mathrm{mg} / \mathrm{kg} /$ day $)$ did not improve the outcome of critically ill patients with AKI (HR 0.870; 95\% CI 0.742-1.020; $P=0.085$ ) (Additional file 1: Table S4).

\section{Subgroup analysis}

The number of patients in each subgroup was showed in Table S5 (see Additional file 1). As shown in Table S6 (see Additional file 1) and Fig. 2, the furosemide was associated with improved in-hospital mortality in patients with AKI stage 1 to 3 according to the KDIGO criteria. When AKI stage was defined by $\mathrm{SCr}$ criteria $\left(\mathrm{AKI}^{\mathrm{SCr}}\right)$, the improved outcome was observed in patients with $\mathrm{AKI}^{\mathrm{SCr}}$ stage 0 or 1 but not in those with $\mathrm{AKI}^{\mathrm{SCr}}$ stage 2 or 3. Interestingly, when AKI stage was defined by UO criteria alone $\left(\mathrm{AKI}^{\mathrm{UO}}\right)$, furosemide was associated with improved in-hospital mortality in patients with $\mathrm{AKI}^{\mathrm{UO}}$ stage 2 or 3 but not in those with $\mathrm{AKI}^{\mathrm{UO}}$ stage 0 or 1 . When the analysis was restricted to patients with CKD, furosemide was not associated with improved in-hospital outcomes. Other subgroups were not significant.

The characteristics of patients with different stages of AKI were shown in Table S7. There were 23.2\% and $36.9 \%$ of cases with positive fluid balance in patients with $\mathrm{AKI}^{\mathrm{UO}}$ stage $0-1$ and $\mathrm{AKI}^{\mathrm{UO}}$ stage 2-3, respectively. Additionally, the proportion of patients 
Table 1 Baseline characteristics between groups before matching

\begin{tabular}{|c|c|c|c|c|}
\hline Variables & $\begin{array}{l}\text { Non-diuretic group } \\
n=6269\end{array}$ & $\begin{array}{l}\text { Furosemide group } \\
n=7885\end{array}$ & $P$ value & SMD \\
\hline AKI stage, $n(\%)$ & & & $<0.001$ & 0.132 \\
\hline Stage 1 & 1953(31.2) & 2293(29.1) & & \\
\hline Stage 2 & 2715(43.3) & 3908(49.6) & & \\
\hline Stage 3 & $1601(25.5)$ & $1684(21.4)$ & & \\
\hline Age & $67.8(54.7,78.9)$ & $69.9(59.2,79.4)$ & $<0.001$ & 0.167 \\
\hline Gender, male, $n(\%)$ & $3503(55.9)$ & $4419(56.0)$ & 0.844 & 0.003 \\
\hline Ethnicity, n (\%) & & & $<0.001$ & 0.125 \\
\hline White & $4271(68.1)$ & $5758(73.0)$ & & \\
\hline Black & $721(11.5)$ & $648(8.2)$ & & \\
\hline Others & $1277(20.4)$ & 1479(18.8) & & \\
\hline Admission type, $n(\%)$ & & & $<0.001$ & 0.424 \\
\hline Elective surgery & $421(6.7)$ & $1575(20.0)$ & & \\
\hline Emergency surgery & $1073(17.1)$ & $1554(19.7)$ & & \\
\hline Medical & $4775(76.2)$ & $4756(60.3)$ & & \\
\hline \multicolumn{5}{|l|}{ Co-morbidities, $n$ (\%) } \\
\hline CKD & $639(10.2)$ & $661(8.4)$ & $<0.001$ & 0.062 \\
\hline Diabetes & 1969 (31.4) & 2637 (33.4) & 0.011 & 0.043 \\
\hline Heart failure & $1774(28.3)$ & $3733(47.3)$ & $<0.001$ & 0.401 \\
\hline Chronic lung disease & $1151(18.4)$ & $1806(22.9)$ & $<0.001$ & 0.112 \\
\hline Chronic liver disease & $649(10.4)$ & $558(7.1)$ & $<0.001$ & 0.116 \\
\hline Cancer & $419(6.7)$ & $314(4.0)$ & $<0.001$ & 0.120 \\
\hline Hypertension & $3431(54.7)$ & $4985(63.2)$ & $<0.001$ & 0.173 \\
\hline Sepsis & 2484 (39.6) & 3607 (45.7) & $<0.001$ & 0.124 \\
\hline ARDS & $1413(22.5)$ & $1857(23.5)$ & 0.156 & 0.024 \\
\hline Acute lung edema & $27(0.4)$ & $91(1.2)$ & $<0.001$ & 0.082 \\
\hline Cardiac surgery & $252(4.0)$ & $1755(22.3)$ & $<0.001$ & 0.561 \\
\hline Mechanical ventilation, no. (\%) & $3016(48.1)$ & $5654(71.7)$ & $<0.001$ & 0.496 \\
\hline RRT, $n(\%)$ & $383(6.1)$ & $293(3.7)$ & $<0.001$ & 0.111 \\
\hline MAPa & $79.3(68.0,93.0)$ & $78.0(68.0,90.0)$ & $<0.001$ & 0.082 \\
\hline Vasopressors use, $n$ (\%) & $2616(41.7)$ & $4832(61.3)$ & $<0.001$ & 0.399 \\
\hline Inotropes use, n (\%) & $301(4.8)$ & $1135(14.4)$ & $<0.001$ & 0.330 \\
\hline Fluid balance & & & $<0.001$ & 0.144 \\
\hline Volume (ml) & $-615(-1500,450)$ & $-393(-1440,1025)$ & & \\
\hline Positive, $n$ (\%) & 1968(31.4) & $3058(38.8)$ & & \\
\hline Daily fluid input (ml) & $201(0,580)$ & $289(51,756)$ & $<0.001$ & 0.084 \\
\hline Colloid input & $378(6.0)$ & $969(12.3)$ & $<0.001$ & 0.218 \\
\hline Serum creatinine ${ }^{a}$ & 114.9(79.6203.3) & $106.1(79.6168 .0)$ & $<0.001$ & 0.191 \\
\hline eGFR, ml/min/1.73 $\mathrm{m}^{2 \mathrm{~b}}$ & $49.9(23.5,82.0)$ & $56.4(30.9,81.9)$ & $<0.001$ & 0.097 \\
\hline SAPSII score ${ }^{c}$ & $39(30,50)$ & $39(32,48)$ & 0.745 & 0.010 \\
\hline
\end{tabular}

Abbreviations: $C K D$ chronic kidney diseases, $A R D S$ acute respiratory distress syndrome, $R R T$ renal replacement therapy, IQR interquartile range, $M A P$ mean arterial pressure, eGFR estimated glomerular filtration rate, SAPSII Simplified Acute Physiology Score II, SMD standardized mean difference

${ }^{a}$ The first values during the first day after ICU admission were recorded

b eGFR was calculated using MDRD formula

c SAPSII score was calculated within the first $24 \mathrm{~h}$ after the ICU admission using the value associated with the greatest severity of illness 
Table 2 Association between furosemide use and clinical outcomes in critically ill patients with acute kidney injury

\begin{tabular}{|c|c|c|c|c|c|c|}
\hline & Non-diuretic group & Furosemide group & $P$ value & $\mathrm{HR}$ & Lower 95\% Cl & Upper 95\% Cl \\
\hline Pre-matched cohort & $n=6269$ & $n=7885$ & & & & \\
\hline \multicolumn{7}{|l|}{ Primary outcome } \\
\hline In-hospital mortality, n (\%) & $1363(21.7)$ & $1001(12.7)$ & $<0.001$ & 0.63 & 0.58 & 0.69 \\
\hline \multicolumn{7}{|l|}{ Secondary outcomes } \\
\hline 90-day mortality, n (\%) ${ }^{a}$ & 1981(31.6) & $1673(21.2)$ & $<0.001$ & 0.66 & 0.61 & 0.70 \\
\hline Recovery of renal function, $n(\%)^{b}$ & 2939(46.9) & 4209(53.4) & $<0.001$ & 1.29 & 1.21 & 1.38 \\
\hline Length of ICU stay, [median (IQR) $]^{c}$ & $3.91(2.8,6.8)$ & $4.13(2.9,7.4)$ & 0.003 & 1.44 & 1.28 & 1.62 \\
\hline Length of hospital stay, [median (IQR) $]^{c}$ & $9.57(6.0,16.2)$ & $10.08(6.8,16.3)$ & 0.013 & 1.37 & 1.12 & 1.68 \\
\hline Post-matched cohort & $n=4427$ & $n=4427$ & & & & \\
\hline \multicolumn{7}{|l|}{ Primary outcome } \\
\hline In-hospital mortality, n (\%) & 974(22.0) & $635(14.3)$ & $<0.001$ & 0.67 & 0.60 & 0.74 \\
\hline \multicolumn{7}{|l|}{ Secondary outcomes } \\
\hline 90-day mortality, $n(\%)^{a}$ & 1442(32.6) & 1054(23.8) & $<0.001$ & 0.69 & 0.64 & 0.75 \\
\hline Recovery of renal function, $n(\%)^{b}$ & $2620(59.2)$ & 2991(67.6) & $<0.001$ & 1.44 & 1.31 & 1.57 \\
\hline Length of ICU stay, [median (IQR) $]^{c}$ & $4.1(2.9,7.1)$ & $4.1(2.9,7.2)$ & 0.221 & 1.28 & 0.89 & 1.62 \\
\hline Length of hospital stay, [median (IQR) $]^{c}$ & $10.0(6.4,16.9)$ & $10.5(6.5,16.4)$ & 0.032 & 1.71 & 1.04 & 2.85 \\
\hline
\end{tabular}

Abbreviations: $H R$ hazard ratio, $C l$ confidence interval, ICU intensive care unit, IQR interquartile range

${ }^{a}$ Cox regression was used for estimating the impact of furosemide use on mortality outcomes adjusting for confounding variables selected based on $P$ value $<$ 0.05 in univariate analysis

${ }^{\mathrm{b}}$ Recovery from acute kidney injury was defined as being discharged from ICU with serum creatinine below 1.5 times the baseline value and normal urine output ( $>0.5 \mathrm{ml} / \mathrm{kg} / \mathrm{h}$ ). Impact of furosemide use on the recovery of renal function was estimated using the logistic regression model

${ }^{c}$ Linear regression was used to evaluate the association between furosemide use and length of stay. HR was calculated using the formula HR $=e^{\beta i}$

with positive fluid balance in $\mathrm{AKI}^{\mathrm{SCr}}$ stage $2-3$ was greater than that in $\mathrm{AKI}^{\mathrm{SCr}}$ stage $0-1 \quad(P<0.001)$ (Additional file 1: Table S7).

\section{Discussion}

Our results demonstrated furosemide administration was associated with reduced short-term mortality in critically ill patients with AKI. The results of the present cohort also suggest that furosemide may promote renal function recovery. Consistent with our study, a previous controlled study found that furosemide appeared to increase renal function recovery rates [19]. Theoretically, furosemide may prevent AKI by decreasing the GFR and tubular workload, and then reduce renal medullary oxygenation [20, 21]. Additionally, some scholars assumed that furosemide could act as renal vasodilators [22]. However, these theoretical arguments were proved in experimental conditions, but not in clinical practice. The results of several previous studies and meta-analysis did not support the use of furosemide in AKI patients [3-5, 23 ], and the KDIGO clinical practice guideline for AKI also suggested against the use of diuretics in AKI management [7]. A recent meta-analysis of 28 randomized controlled trials found that furosemide administration was not associated with increased mortality in patients with or at risk for AKI, and it may reduce mortality when used as a preventive measure [24]. Unfortunately, the severity and fluid status of AKI was not included in the study [24]. It is necessary to further analyze the influence of furosemide on outcomes in different subsets of AKI patients.

Oliguria still represents one of the two main criteria for the diagnosis of AKI, and it is also the main reason for using diuretics. In our cohort, there were 7244 (82\%) patients with AKI according to UO criteria alone. Positive fluid balance is an expected complication of oliguria in AKI patients. Furosemide is helpful in the management of fluid overload. The results of the present study showed that positive fluid balance was more common in patients with AKI oliguria stage 2-3, and beneficial effect of furosemide on in-hospital mortality was especially observed in this population. A multicenter ICU study also found that, in patients with a higher fluid balance and a lower volume of urine output, diuretic use was associated with better survival [25]. So, the beneficial effects of furosemide on mortality in oliguric AKI patients may be mediated by fluid balance.

Unlike $\mathrm{SCr}$ criteria, defining AKI with the UO criteria may be too liberal because several studies illustrated that AKI defined by UO was not an independent predictor of mortality [26, 27], and oliguria was not always indicative of a reduced GFR or tubular dysfunction [28]. In AKI patients with an increase in $\mathrm{SCr}$ by two or more times the baseline, we found that furosemide use was not associated with a significant decrease in in-hospital mortality, even in those accompanied by UO less than $0.5 \mathrm{ml} / \mathrm{kg}$ 


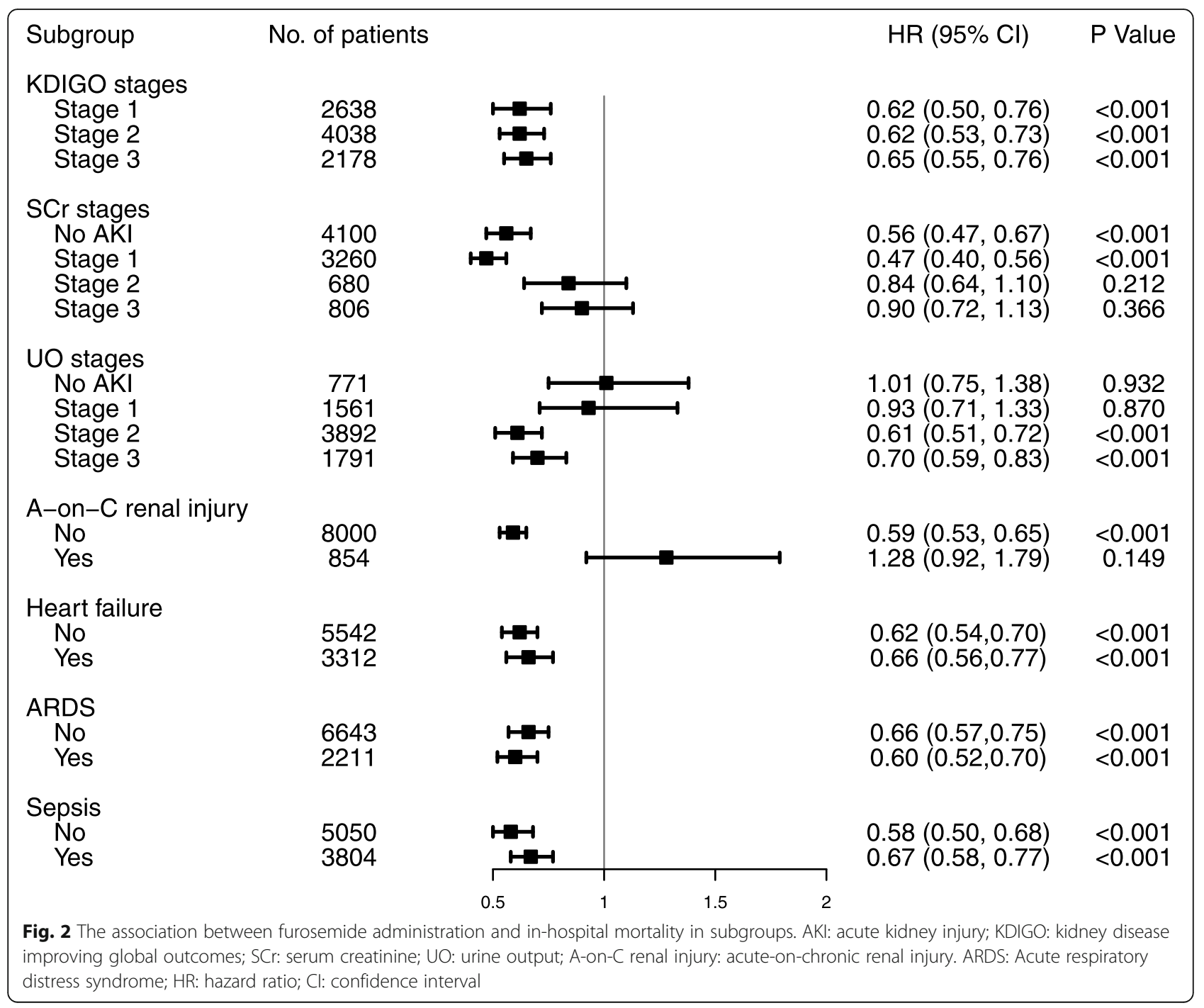

for more than $12 \mathrm{~h}$ (data not shown). In fact, Shen et al. have noticed that the effect of furosemide on mortality in AKI patients depends on the levels of $\mathrm{SCr}$, and that the association between increased risk of death and furosemide was more frequently reported in cohorts with higher $\mathrm{SCr}[3,8,12]$. So, urine volume output and the levels of $\mathrm{SCr}$ need to be considered together when using diuretics to treat AKI.

AKI patients with prior CKD, named acute-on-chronic (A-on-C) renal injury, is commonly seen in clinical practice with an incidence ranging from 13 to 35 per 100 AKI patients $[29,30]$. In the pre-matched cohort, the incidence of A-on-C renal injury was $9.2 \%$. More and more evidence suggest that epidemiological characteristics and outcomes of patients with A-on-C renal injury differ from AKI patients without prior CKD [29-31]. Nevertheless, the effect of furosemide on outcomes of A-on- $C$ renal injury remains exclusive. In the present study, we first found that furosemide use was not associated with improved short-term survival in patients with A-on-C renal injury.

Our study has important limitations. Most notably, the MIMIC III database used in the present study only contains the data of critically ill patients admitted between 2001 and 2012. The definition of AKI has evolved in 2012. Thus, it is possible that our cohort is not exactly meeting the new definition of AKI. However, we have tried to identify AKI patients according to the newest criteria for AKI diagnosis (KDIGO criteria). Second, changes in treatment strategies for critically ill patients, including metabolism and nutritional support strategies and methods of mechanical ventilation, may influence the outcomes of AKI. However, there is no direct evidence which shows that these factors associated with the efficacy of furosemide in critically ill patients with AKI, and the clinical practice of AKI have not changed significantly in the past two decades. Third, only AKI patients receiving furosemide within $48 \mathrm{~h}$ after admission were 
included for analysis in our study. So, the effect of delayed use of furosemide on outcomes of AKI needs to be further investigated. Fourth, although the sample size of subgroups of the present study is relatively larger than previous studies, multiple subgroup analysis may also increase the risk of false-positive findings. Fifth, it was a retrospective design. Despite careful propensity score matching, residual confounding cannot be fully excluded. So, the risk of confounding factors should be taken into consideration when interpreting the results. Finally, this was a single-center study. The results need to be validated by multicenter trials.

\section{Conclusions}

The use of furosemide was associated with reduced short-term mortality and improved recovery of renal function in critically ill patients with AKI. Furosemide was especially effective in patients with AKI oliguria stage 2-3 degree, but not in those with AKI SCr stage $2-3$ and chronic kidney disease. Our results may be helpful for the rational use of furosemide in critically ill patients with AKI. The results need to be verified in the future by multicenter randomized controlled trials.

\section{Supplementary information}

Supplementary information accompanies this paper at https://doi.org/10 1186/s13054-020-2798-6.

Additional file 1: Table S1. Missing number (\%) for risk variables and outcome variables. Table S2. Potential risk variables for in-hospital death. Table S3. Comparisons after propensity score matching. Table S4. doseresponse relationship between furosemide administration and in-hospital mortality. Table S5. The number of patients in subgroups. Table S6. The association between furosemide use and in-hospital mortality in subgroups. Table S7. the characteristics of patients with different stages of AKI. Figure S1. Standardized mean difference (SMD) of variables before and after propensity score matching.

\begin{abstract}
Abbreviations
AKl: Acute kidney injury; A-on-C renal injury: Acute-on-chronic renal injury; Cl: Confidence interval; D-AKI: Dialysis requiring acute kidney injury; eGFR: Estimated glomerular filtration rate; HR: Hazard ratio; ICU: Intensive care unit; ICU: Intensive care unit; IQR: Interquartile range; KDIGO: Kidney disease: improving global outcomes; MAP: Mean arterial pressure; MDRD: Modification of diet in renal disease; MIMIC III: Multiparameter Intelligent Monitoring in Intensive Care Database III; RRT: Renal replacement therapy; SAPSII: Simplified Acute Physiology Score II; SCr: Serum creatinine; SMD: Standardized mean difference; UO: Urine output
\end{abstract}

\section{Authors' contributions}

GJZ designed the study, collected and analyzed data, and contributed to writing this manuscript. CX collected and analyzed data. WBL, GLH, MFL, and BW helped with data analyzation. YMY and ZQL designed and supervised the study and drafted the manuscript. All authors have read and approved the final manuscript.

\section{Funding}

This work was supported, in part, by grants from the National Natural Science Foundation of China (81571937, 81772112, 81871583).

\section{Availability of data and materials}

The datasets used in the present study are available from the first author and corresponding authors on reasonable request.

\section{Ethics approval and consent to participate}

MIMIC III database used in the present study was approved by the Institutional Review Boards (IRB) of the Massachusetts Institute of Technology and does not contain protected health information.

\section{Consent for publication}

Not applicable.

\section{Competing interests}

The authors declare that they have no competing interests.

Received: 19 November 2019 Accepted: 18 February 2020

Published online: 04 March 2020

References

1. Ejaz AA, Mohandas R. Are diuretics harmful in the management of acute kidney injury? Curr Opin Nephrol Hypertens. 2014;23:155-60.

2. Grams ME, Estrella MM, Coresh J, Brower RG, Liu KD. Fluid balance, diuretic use, and mortality in acute kidney injury. Clin J Am Soc Nephrol. 2011;6: 966-73

3. Mehta RL, Pascual MT, Soroko S, Chertow GM. Diuretics, mortality, and nonrecovery of renal function in acute renal failure. JAMA. 2002;288:2547-53.

4. Krzych LJ, Czempik PF. Impact of furosemide on mortality and the requirement for renal replacement therapy in acute kidney injury: a systematic review and meta-analysis of randomised trials. Ann Intensive Care. 2019;9:85

5. Mahesh B, Yim B, Robson D, Pillai R, Ratnatunga C, Pigott D. Does furosemide prevent renal dysfunction in high-risk cardiac surgical patients? Results of a double-blinded prospective randomised trial. Eur J Cardiothorac Surg. 2008:33:370-6

6. Eckardt KU, Kasiske BL. Kidney disease: improving global outcomes. Nat Rev Nephrol. 2009:5:650-7.

7. Levin A, Stevens PE, Bilous RW, Coresh J, Francisco A, Jong PE, et al. Kidney disease: improving global outcomes (KDIGO) CKD work group. KDIGO 2012 clinical practice guideline for the evaluation and management of chronic kidney disease. Kidney Int Suppl. 2013:3:1-150.

8. Bagshaw SM, Gibney RTN, Kruger P, Hassan I, McAlister FA, Bellomo R. The effect of low-dose furosemide in critically ill patients with early acute kidney injury: a pilot randomized blinded controlled trial (the SPARK study). J Crit Care. 2017:42:138-46.

9. Kellum JA, Sileanu FE, Murugan R, Lucko N, Shaw AD, Clermont G. Classifying AKI by urine output versus serum Creatinine level. J Am Soc Nephrol. 2015:26:2231-8.

10. Wlodzimirow KA, Abu-Hanna A, Slabbekoorn M, Chamuleau RA, Schultz MJ, Bouman CS. A comparison of RIFLE with and without urine output criteria for acute kidney injury in critically ill patients. Crit Care. 2012;16:R200.

11. Macedo E, Malhotra R, Claure-Del Granado R, Fedullo P, Mehta RL. Defining urine output criterion for acute kidney injury in critically ill patients. Nephrol Dial Transplant. 2011;26:509-15

12. Shen $Y$, Wu M. Loop diuretic use in patients with AKl: different severity, different response. Crit Care. 2018;22:202.

13. Johnson AE, Pollard TJ, Shen L, Lehman LW, Feng M, Ghassemi M, et al. MIMIC-III, a freely accessible critical care database. Sci Data. 2016;3:160035.

14. Zhang Z, Zhu C, Mo L, Hong Y. Effectiveness of sodium bicarbonate infusion on mortality in septic patients with metabolic acidosis. Intensive Care Med. 2018;44:1888-95.

15. Siew ED, Ikizler TA, Matheny ME, Shi Y, Schildcrout JS, Danciu I, et al. Estimating baseline kidney function in hospitalized patients with impaired kidney function. Clin J Am Soc Nephrol. 2012;7(5):712-9.

16. Huber M, Ozrazgat-Baslanti T, Thottakkara P, Scali S, Bihorac A, Hobson C. Cardiovascular-specific mortality and kidney disease in patients undergoing vascular surgery. JAMA Surg. 2015;151(5):1-10.

17. Angeli $P$, Gines $P$, Wong $F$, Bernardi $M$, Boyer TD, Gerbes A, Moreau R, Jalan R, Sarin SK, Piano S, et al. Diagnosis and management of acute kidney injury in patients with cirrhosis: revised consensus recommendations of the International Club of Ascites. J Hepatol. 2015;62(4):968-74. 
18. Perez Valdivieso JR, Bes-Rastrollo M, Monedero P, De Irala J, Lavilla FJ. Evaluation of the prognostic value of the risk, injury, failure, loss and endstage renal failure (RIFLE) criteria for acute kidney injury. Nephrology (Carlton). 2008:13:361-6.

19. Cantarovich F, Galli C, Benedetti L, Chena C, Castro L, Correa C, et al. High dose frusemide in established acute renal failure. Br Med J. 1973:4:449-50

20. Epstein FH, Prasad P. Effects of furosemide on medullary oxygenation in younger and older subjects. Kidney Int. 2000;57:2080-3.

21. Peixoto AJ. Update in nephrology and hypertension: evidence published in 2015. Ann Intern Med. 2016;164:W42-7.

22. Kellum JA. Diuretics in acute renal failure: protective or deleterious. Blood Purif. 1997;15:319-22.

23. van der Voort PH, Boerma EC, Koopmans M, Zandberg M, de Ruiter J, Gerritsen RT, et al. Furosemide does not improve renal recovery after hemofiltration for acute renal failure in critically ill patients: a double blind randomized controlled trial. Crit Care Med. 2009;37:533-8.

24. Bove T, Belletti A, Putzu A, Pappacena S, Denaro G, Landoni G, et al. Intermittent furosemide administration in patients with or at risk for acute kidney injury: Meta-analysis of randomized trials. Plos One. 2018;13(4): e0196088.

25. Teixeira C, Garzotto F, Piccinni P, Brienza N, lannuzzi M, Gramaticopolo S, et al. Fluid balance and urine volume are independent predictors of mortality in acute kidney injury. Crit Care. 2013;17(1):R14.

26. Md Ralib A, Pickering JW, Shaw GM, Endre ZH. The urine output definition of acute kidney injury is too liberal. Crit Care. 2013;17:R112.

27. Cruz DN, Bolgan I, Perazella MA, Bonello M, de Cal M, Corradi V, et al. North east Italian prospective hospital renal outcome survey on acute kidney injury (NEiPHROS-AKI): targeting the problem with the RIFLE criteria. Clin J Am Soc Nephrol. 2007;2:418-25.

28. Danovitch G, Carvounis C, Weinstein E, Levenson S. Nonoliguric acute renal failure. Isr J Med Sci. 1979;15:5-8.

29. Ali T, Khan I, Simpson W, Prescott G, Townend J, Smith W, et al. Incidence and outcomes in acute kidney injury: a comprehensive population-based study. J Am Soc Nephrol. 2007;18:1292-8.

30. Prakash J, Rathore SS, Arora P, Ghosh B, Singh TB, Gupta T, et al,

Comparison of clinical characteristics of acute kidney injury versus acute-onchronic renal failure: our experience in a developing country. Hong Kong J Nephrol. 2015;17:14-20.

31. Wu VC, Huang TM, Lai CF, Shiao CC, Lin YF, Chu TS, et al. Acute-on-chronic kidney injury at hospital discharge is associated with long-term dialysis and mortality. Kidney Int. 2011;80:1222-30.

\section{Publisher's Note}

Springer Nature remains neutral with regard to jurisdictional claims in published maps and institutional affiliations.

Ready to submit your research? Choose BMC and benefit from:

- fast, convenient online submission

- thorough peer review by experienced researchers in your field

- rapid publication on acceptance

- support for research data, including large and complex data types

- gold Open Access which fosters wider collaboration and increased citations

- maximum visibility for your research: over $100 \mathrm{M}$ website views per year

At $\mathrm{BMC}$, research is always in progress.

Learn more biomedcentral.com/submissions 